\title{
Genetically engineered pigs and target-specific immunomodulation provide significant graft survival and hope for clinical cardiac xenotransplantation
}

\author{
Muhammad M. Mohiuddin, MD, ${ }^{\text {a }}$ Avneesh K. Singh, PhD, ${ }^{a}$ Philip C. Corcoran, MD, ${ }^{a}$ \\ Robert F. Hoyt, DVM, ${ }^{\mathrm{b}}$ Marvin L. Thomas III, DVM, ${ }^{\mathrm{c}}$ David Ayares, PhD, ${ }^{\mathrm{d}}$ and Keith A. Horvath, $\mathrm{MD}^{\mathrm{a}}$
}

\begin{abstract}
Objectives: Cardiac transplantation and available mechanical alternatives are the only possible solutions for end-stage cardiac disease. Unfortunately, because of the limited supply of human organs, xenotransplantation may be the ideal method to overcome this shortage. We have recently seen significant prolongation of heterotopic cardiac xenograft survival from 3 to 12 months and beyond.
\end{abstract}

\begin{abstract}
Methods: Hearts from genetically engineered piglets that were alpha 1-3 galactosidase transferase knockout and expressed the human complement regulatory gene, CD46 (groups A-C), and the human thrombomodulin gene (group D) were heterotropically transplanted in baboons treated with antithymocyte globulin, cobra venom factor, anti-CD20 antibody, and costimulation blockade (anti-CD154 antibody [clone 5C8]) in group A, anti-CD40 antibody (clone 3A8; $20 \mathrm{mg} / \mathrm{kg}$ ) in group B, clone 2C10R4 $(25 \mathrm{mg} / \mathrm{kg})$ in group C, or clone 2C10R4 $(50 \mathrm{mg} / \mathrm{kg}$ ) in group $\mathrm{D}$, along with conventional nonspecific immunosuppressive agents.
\end{abstract}

Results: Group A grafts $(n=8)$ survived for an average of 70 days, with the longest survival of 236 days. Some animals in this group $(n=3)$ developed microvascular thrombosis due to platelet activation and consumption, which resulted in spontaneous hemorrhage. The median survival time was 21 days in group $\mathrm{B}(\mathrm{n}=3), 80$ days in group C $(n=6)$, and more than 200 days in group $\mathrm{D}(\mathrm{n}=5)$. Three grafts in group $\mathrm{D}$ are still contracting well, with the longest ongoing graft survival surpassing the 1-year mark.

Conclusions: Genetically engineered pig hearts (GTKOhTg.hCD46.hTBM) with modified targeted immunosuppression (anti-CD40 monoclonal antibody) achieved long-term cardiac xenograft survival. This potentially paves the way for clinical xenotransplantation if similar survival can be reproduced in an orthotopic transplantation model. (J Thorac Cardiovasc Surg 2014;148:1106-14)

Patients with end-stage organ failure waiting for donor organs have limited treatment options. For those with cardiac failure, mechanical assist devices provide one solution, but various complications associated with these devices have reduced their effectiveness. ${ }^{1}$ Until we learn to grow organs via tissue engineering, which is unlikely in the near future, xenotransplantation seems to be a valid approach to supplement human organ availability. Despite

From the Cardiothoracic Surgery Research Program, ${ }^{a}$ National Heart, Lung, and Blood Institute, National Institutes of Health, Bethesda, Md; Laboratory Animal Sciences Program, ${ }^{\text {b }}$ Leidos Biomedical Research, Inc, Frederick National Laboratory, Frederick, Md; Division of Veterinary Resources, ${ }^{\mathrm{c}}$ National Institutes of Health, Bethesda, Md; and Revivicor, Inc, ${ }^{\mathrm{d}}$ Blacksburg, Va.

Disclosures: Dr Ayares is the Executive Vice President and Chief Scientific Officer of Revivicor, Inc. All other authors have nothing to disclose with regard to commercial support.

Read at the 94th Annual Meeting of The American Association for Thoracic Surgery, Toronto, Ontario, Canada, April 26-30, 2014.

Received for publication April 4, 2014; revisions received May 29, 2014; accepted for publication June 2, 2014; available ahead of print July 4, 2014.

Address for reprints: Muhammad M. Mohiuddin, MD, CSRP/NHLBI/NIH, Building 10, Rm B1D47G, 10 Center Drive, MSC 1550, Bethesda, MD 20892 (E-mail: mohiuddinm@mail.nih.gov).

$0022-5223 / \$ 36.00$

Copyright $($ C 2014 by The American Association for Thoracic Surgery

http://dx.doi.org/10.1016/j.jtcvs.2014.06.002 many setbacks over the years, 2 major recent developments have helped revitalized progress in the xenotransplantation field. First is the ability to produce genetically engineered (GE) pigs $^{2,3}$ in which certain genes that are immunogenic to humans are knocked out and human transgenes, such as complement regulatory proteins (human complement regulatory protein) and human thromboregulatory protein, are expressed on pig cells. ${ }^{4}$ The second achievement is the development of target-specific immunosuppression that could be used clinically in place of generalized immunosuppression. ${ }^{4}$ With these developments, cardiac xenograft survival has been prolonged to more than 1 year. ${ }^{5}$ Because of the cost of these experiments and scarce research funding, it is not feasible to address each genetic and immunosuppressive manipulation individually. Therefore, laboratories performing experiments in the field of xenotransplantation have selectively picked specific genetic modifications in pigs and immunosuppressive drug combinations to perform xenotransplantation experiments. In this report, we have summarized our results from multiple experiments to show the impact of these GE pigs and target-specific immune suppression focusing on recipient B-cell depletion and costimulation blockade. 

Abbreviations and Acronyms
ACT $=$ activated clotting time
$\mathrm{CMV}=$ cytomegalovirus
$\mathrm{EKG}=$ electrocardiogram
$\mathrm{GE}=$ genetically engineered
Ig = immunoglobulin
IV = intravenously
LVP $=$ left ventricular pressure
$\mathrm{mAb}=$ monoclonal antibody
$\mathrm{SPF}=$ specific pathogen-free
$\mathrm{TBM}=$ thrombomodulin
$\mathrm{TM}=$ thrombotic microangiopathy
$\mathrm{WBC}=$ white blood cell

\section{METHODS}

\section{Animal Models and Genetic Modifications}

Specific pathogen-free (SPF) baboons weighing 7 to $15 \mathrm{~kg}$ from the University of Oklahoma (Norman, Okla) were housed in a clean pathogen-free facility. These SPF baboons are known to have lower levels of both anti-non-Gal immunoglobulin (Ig)G and IgM. ${ }^{6,7}$ Genetically modified pigs (aged 4-8 weeks) that were alpha galactosidase transferase knockout and hCD46 transgenic (GTKO.hCD46), with or without thrombomodulin (TBM) expression (Revivicor Inc, Blacksburg, Va), were used as heart donors. The weights of donor pigs were matched to the baboon recipient to ensure adequate accommodation of the heterotopic heart. All animals were used in compliance with guidelines provided by the National Heart, Lung, and Blood Institute Animal Care and Use Committee. All transplant procedures were performed at a National Heart, Lung, and Blood Institute core surgical facility.

\section{Surgical Procedure}

Donor pig hearts were transplanted into recipient SPF baboons in a heterotopic position, as described previously. ${ }^{8}$ Briefly, the recipient baboon's infrarenal aorta and inferior vena cava were exposed through a midline abdominal incision. Side-biting clamps were applied; an aortotomy and venotomy were made, and the end-to-side anastomosis was performed between the donor and recipient aorta and the donor pulmonary artery with the recipient inferior vena cava.

\section{Immunosuppressive Regimen}

A detailed description of the immunosuppressive regimen is shown in Figure 1. In brief, it includes induction with antithymocyte globulin, anti-CD20 antibody (Rituxan; Genentech, Inc, South San Francisco, Calif), and costimulation blockade with anti-CD154 (5C8) or anti-CD40 (3A8 or 2C10R4) monoclonal antibody (mAb). Cobra venom factor was used to inhibit the complement activation. Mycophenolate mofetil and costimulation blockade antibody were also used daily and weekly as described in Figure 1 to prevent immune rejection. All recipient baboons received continuous heparin infusion to maintain the activated clotting time (ACT) level at twice the baseline. Ganciclovir was administered intravenously (IV) daily to prevent any potential viral infections. Erythropoietin (200 U/kg) was administered IV daily from day -7 to 7 , and cefazolin $(250 \mathrm{mg}$ ) IV was administered twice per day for 7 days.

\section{Experimental Groups}

The experimental groups are described in Table 1, and the duration of immunosuppression is illustrated in Figure 1. The main difference among the 4 groups was the type, strength, and duration of antibody used for costimulation blockade. In group A, anti-CD154 (5C8) (20 mg/kg) IV was used for the entire period of graft survival. In group B, anti-CD40 (3A8) $(20 \mathrm{mg} / \mathrm{kg})$ IV was used for a maximum of 60 days. In group C, anti-CD40 (2C10) $(20 \mathrm{mg} / \mathrm{kg})$ was tapered off in 60 days. In group D, anti-CD40 $(2 \mathrm{C} 10)(50 \mathrm{mg} / \mathrm{kg})$ was continued for 1 year $(\mathrm{n}=2)$ or reduced $(25 \mathrm{mg} / \mathrm{kg})$ after 100 days $(\mathrm{n}=2)$.

\section{Rescue Therapy}

If rejection was suspected by diminution of xenograft function, rescue therapy was initiated with intravenous methyl prednisolone (10$15 \mathrm{mg} / \mathrm{kg}$ ) for 6 days. Heparin was also used to prevent thrombus formation, and activated clotted time (ACT) was maintained at twice the baseline.

\section{Measurement of Graft Survival}

Telemetry, manual palpation, and noninvasive ultrasonography were used to monitor the xenograft function. A telemetry device was implanted at the time of transplantation to monitor the baboon recipient's temperature, graft left ventricular pressure (LVP), and electrocardiogram (EKG). The telemetry device data were transmitted wirelessly to a receiver attached to the animal's cage (RMISS, Wilmington, Del). The parameters were recorded and included the peak systolic pressure, end-diastolic pressure, LVP, heart rate based on LVP, EKG, heart rate based on EKG, and recipient's body temperature. Heart function was continuously evaluated by telemetry, and a decrease in LVP to less than $60 \mathrm{~mm} \mathrm{Hg}$ was correlated with the initiation of the rejection process, which affected the graft contractility. An LVP less than $10 \mathrm{~mm} \mathrm{Hg}$ was an indicator of complete cessation of graft contractility.

Recipients were sedated weekly for the first 2 months post-transplant and biweekly thereafter for blood collection. Palpation and ultrasound were also done on this schedule. On the basis of xenograft palpation, contractility of the heart was scored as ++++ (fully functional) to 0 (nonfunctional). Blood flow and wall motion were analyzed by echocardiography.

\section{Hematology}

White blood cell (WBC) count, hematocrit, red blood cell count, hemoglobin, platelets, neutrophils, and monocytes were analyzed. Blood chemistry was performed weekly for the first 2 months and then biweekly until the graft was explanted or rejected. ACT, prothrombin time, and troponin levels were measured at the same intervals.

\section{Histology}

Paraffin sections from biopsies and explanted xenografts were stained with hematoxylin-eosin for light microscopy. Sections were analyzed for cardiomyocyte viability and the presence of hemorrhage, microvasculature thrombosis, and cellular infiltrates.

\section{RESULTS \\ Graft Survival}

Graft survival curves for all groups are shown in Figure 2, $A$. Median graft survivals of the 4 groups are shown in Figure $2, B$, and the longest survival in each group is shown in Figure 2, C. Among all groups, group D, receiving the high dose of anti-CD40mAb, had the longest median and individual survival. In group A, most of the grafts were still contracting at the time of recipient death or euthanasia because of various complications. All grafts in groups B and $\mathrm{C}$ were rejected. Two of 5 grafts in group D stopped contracting on postoperative days 146 and 159, but the other 


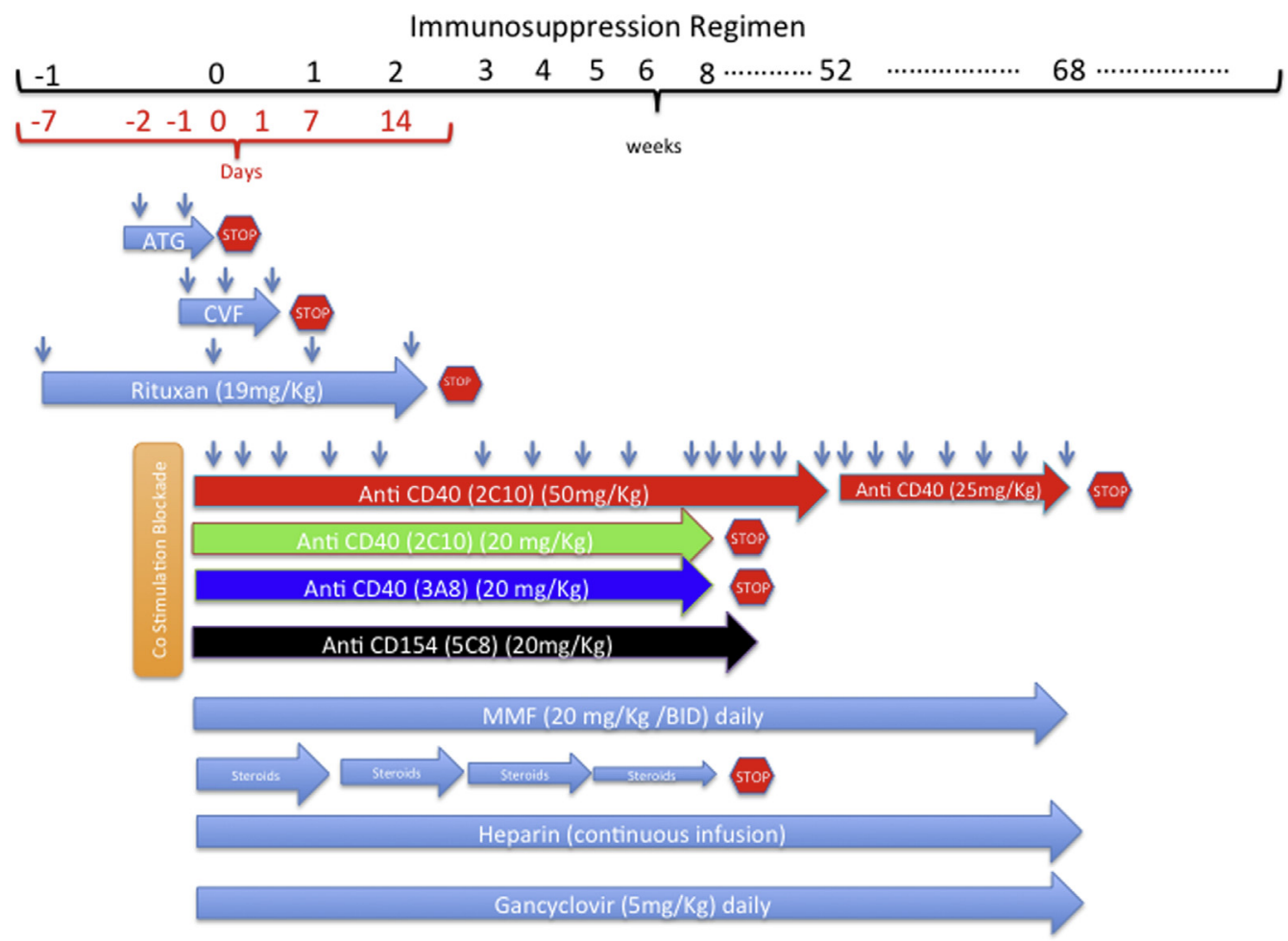

FIGURE 1. Timeline of various immunosuppressive drugs: The red stop sign indicates that the drug was stopped at this point. The duration of antibody treatment in 4 different groups is shown. Antibody in groups A and D was given until the graft was rejected or explanted. ATG, Antithymocyte globulin; BID, twice per day; $C V F$, cobra venom factor; $M M F$, mycophenolate mofetil.

3 grafts are still contracting at more than 200 to 500 days at the time of this submission.

\section{Measurement of Graft Contractility}

Echocardiography was performed only in groups $\mathrm{C}$ and $\mathrm{D}$ (echocardiography machine not available for earlier experiments) receiving 2C10R4mAb and GTKO.hCD46 (group C) or GTKO.hCD46.hTBM (group D) pig heart xenografts. Excellent graft contractility was observed in all animals. The original wall thickness was maintained to the end, but in animals that stopped functioning in both groups, left ventricular and left atrial walls were considerably thickened. Of note, there was no thrombus observed in group D receiving grafts with human TBM expression and high-dose anti-CD40 mAb (2C10R4) treatment.

Telemetry was used to measure LVP and EKG. The heart rate was calculated by the software on the basis of the number of LVP peaks and QRS complexes per minute. Because of limited battery life, telemetry was useful for 200 to 400 days post-transplantation. Three grafts in group D were still functioning to the day of the submission of the article, and telemetry was useful in determining graft function for 230, 250, and 400 days in each. All of the grafts in group $\mathrm{C}$ rejected within 146 days, and telemetry documented a loss of LVP and heart contractility. Manual graft palpation scores were consistent with the findings of ultrasound and telemetry.

\section{Depletion of T and B Cells and the Effect on Non-Gal Antibody Production}

Initial treatment with ATG significantly reduced the number of circulating $T$ cells, but they were not totally eliminated. However, treatment with 4 weekly doses of antiCD20 effectively depleted all of the circulating B cells,

TABLE 1. Description of the 4 experimental groups: The difference in the 4 experimental groups is described, including the antibody for costimulation blockade and B-cell depletion in each group

\begin{tabular}{lllll}
\hline Group & \multicolumn{1}{c}{ Pig genetics } & n & Costimulation blockade & B-cell depletion \\
\hline A & GTKO.hCD46Tg & 8 & Anti-CD154 (5C8) & Anti-CD20 \\
B & GTKO.hCD46Tg & 3 & Anti-CD40 (3A8) & Anti-CD20 \\
C & GTKO.hCD46Tg & 6 & Anti-CD40 (2C10R4) Low dose & Anti-CD20 \\
D & GTKO.hCD46Tg.hTBM & 5 & Anti-CD40 (2C10R4) High dose & Anti-CD20 \\
\hline
\end{tabular}




\section{Graft Survival}

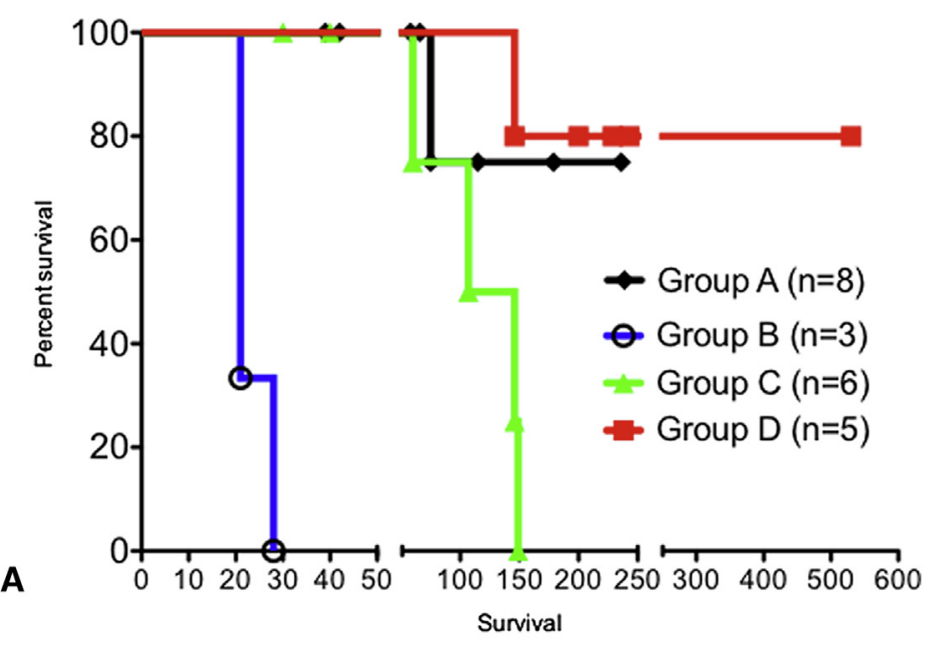

Median Survival

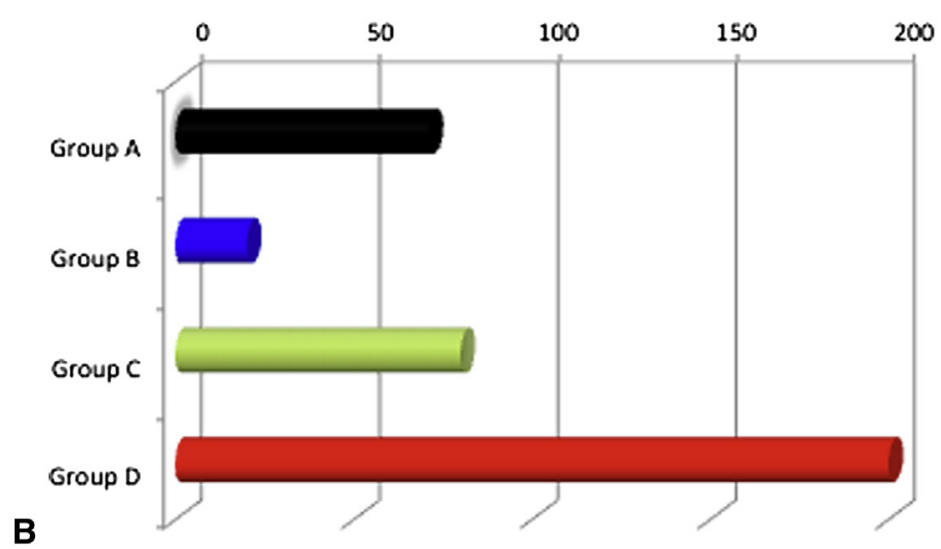

Longest Survival

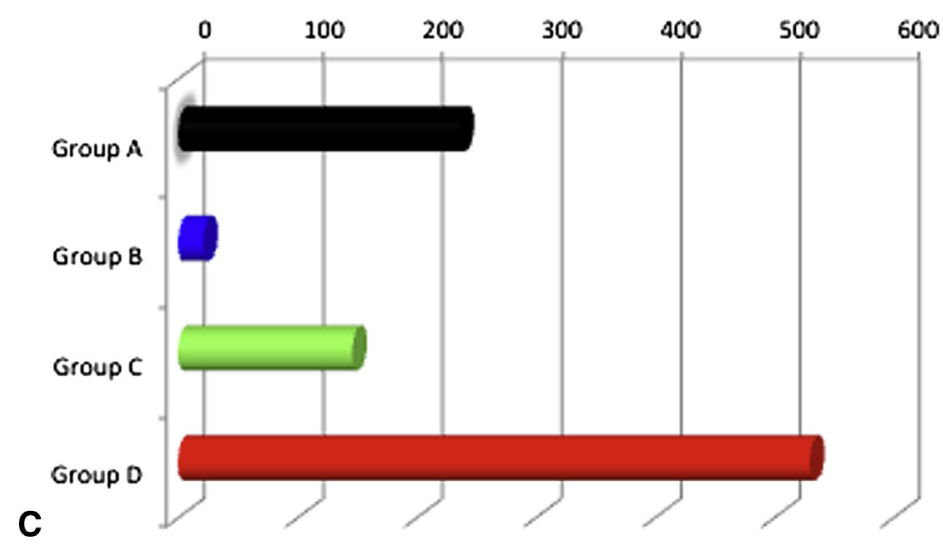

FIGURE 2. Graft survival: A, Survival days for grafts in all groups are shown. B, Median survival time of xenografts in each group is shown. C, Longest survival time in each group is shown. 
and they stayed depleted for at least 60 days, after which they were slowly restored to pretreatment levels. ${ }^{6,9}$ Although anti-CD20 has no direct affect on plasma cells, the non-Gal antibody production was maintained at a low level by this treatment.

\section{Complete Blood Count, Chemistry, and Coagulation Profile}

Figure 3 shows the comparison of WBC count, platelet count, hematocrit, and hemoglobin levels. The treatment regimen was effective in keeping WBC counts low in all 4 groups. The median platelet numbers were maintained better with 2C10R4 mAb treatment, but only group $\mathrm{C}$ platelet counts were significantly better than in the other 3 groups. The hemoglobin level and hematocrit percentage were kept close to normal in all groups, and there was no significant difference among the groups. Anemia and thrombocytopenia were treated with a transfusion of packed red blood cells as needed.

\section{Graft Histology}

Graft histology in group A showed small areas of normal myocardium along with significant areas of hemorrhage, coagulative necrosis, and fibrosis. Some thrombotic microangiopathy (TM) was observed in this group. No TM was observed in groups $\mathrm{B}, \mathrm{C}$, or D. Rejected grafts in groups $\mathrm{B}, \mathrm{C}$, and $\mathrm{D}$ showed some myofibril loss with fibrosis, but there was only minimal hemorrhage present. Figure 4 shows a representative hematoxylin-eosin staining of a left ventricle from the group A graft, showing widespread areas of fibrosis, along with some normal myocytes, and a biopsy specimen from a group $\mathrm{D}$ heart taken at 182 days postoperatively, showing primarily normal myocytes and a small area of fibrosis.

\section{Complications}

Most animals in group A had to be euthanized or died of various complications (eg, abdominal bleeding, aspiration pneumonia, and consumptive coagulopathy). Infections were rare in all the groups and if noticed were managed by antibiotic treatment after culture and sensitivity testing was performed. Few complications were seen in groups $\mathrm{B}, \mathrm{C}$, and D. In these groups, most of the heart xenografts were explanted after rejection, and recipient baboons survived.

\section{DISCUSSION}

The availability of GE pigs has transformed the field of xenotransplantation and rejuvenated the hopes for clinical xenotransplantation. However, there are parts of this puzzle that still need to be solved. ${ }^{10,11}$ Some of the major obstacles, after overcoming the Gal antibody barrier, include the presence of preformed and elicited non-Gal antibodies against multiple antigens, ${ }^{12}$ consumptive coagulopathy caused by rapid depletion of platelets, ${ }^{13}$ and TM due to an induced hypercoagulable state. ${ }^{14}$

Our laboratory, in collaboration with other groups, has made several inroads in this field. Conventional immunosuppression has been tried in this model, and these agents reasonably prolonged the graft survival. ${ }^{15,16}$ We have tried to improve on the conventional immunosuppression with the use of target-specific immunosuppressive agents, which, along with the use of newly available GE pigs, have significantly improved the graft survival of pig cardiac xenografts in baboons.

The first step toward improvement in graft survival was observed with B-cell depletion via anti-CD20 mAb. The possible mechanisms of depletion include direct lysis via natural killer cells/macrophages, antibody-mediated cell cytotoxicity, and complement-dependent cytotoxicity. ${ }^{17}$ Only 4 doses of anti-CD20 mAb on days $-7,0,7$, and 14 were able deplete the B-cell population for 2 months. The research group at the Mayo Clinic (Rochester, Minn) has shown that 1 dose can deplete circulating B cells effectively, but 4 doses are required to deplete $B$ cells from the lymphoid organs (Gerry Byrne, personal communication, October 2011). Although this anti-B-cell treatment was not effective for plasma cell depletion, because plasma cells do not express CD20, the levels of both anti-non-Gal IgM and $\mathrm{IgG}$ remained at very low levels because of this treatment, and signs of antibody-mediated rejection were not seen in any animals receiving anti-CD20 mAb treatment. Of note, we have reported that the cardiac xenografts do show some minor deposition of anti-non-Gal antibodies. ${ }^{6}$ There was a moderate increase in non-Gal antibody levels after 60 days of survival, but no obvious signs of rejection were observed. Perhaps the xenograft is "accommodated" by this time or a state of "immune tolerance" is induced. Currently, studies are being performed to evaluate these mechanisms. There may be a benefit of continuous suppression of B cells by anti-CD20 antibody beyond 60 days. The anti-CD40 antibody used in these experiments also suppresses the B-cell response and may be sufficient to keep the B-cell response under control after 60 days.

The costimulation blockade pathway was critical to graft survival, because suppression of this pathway modulates the response of both $\mathrm{B}$ and $\mathrm{T}$ cells. In the initial experiments, we targeted the CD40-CD40Ligand pathway by using antiCD154 mAb, which yielded the previous longest cardiac xenograft survival of 236 days. The use of this antibody in some cases, because of expression of CD154 on platelets and binding of anti-CD154 to the platelets resulting in their activation and aggregation, was accompanied by fatal coagulopathies leading to euthanasia or death of recipient baboons before graft rejection. ${ }^{6,18}$ This is a known complication of this antibody, and as a result anti-CD154 $\mathrm{mAb}$ is not recommended for clinical use. ${ }^{19,20}$ However, the experiments with this antibody demonstrated the 
WBC

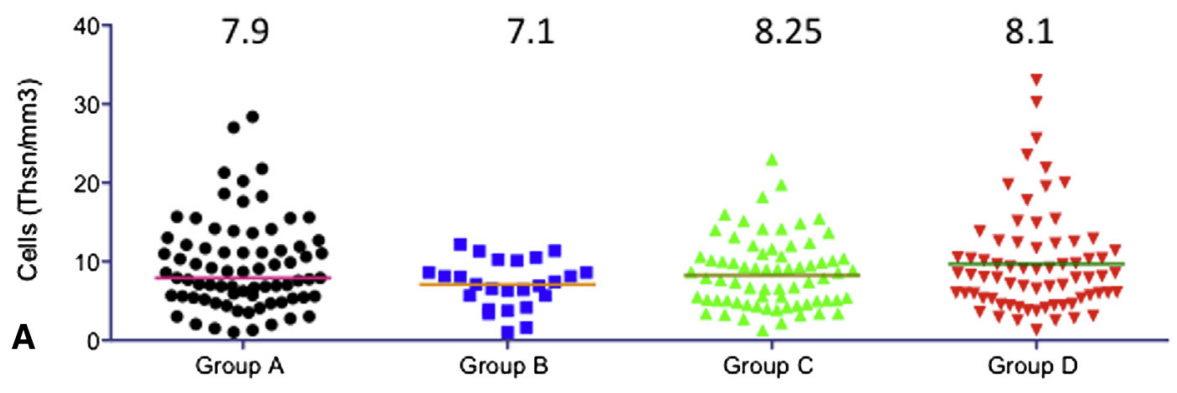

Platelets

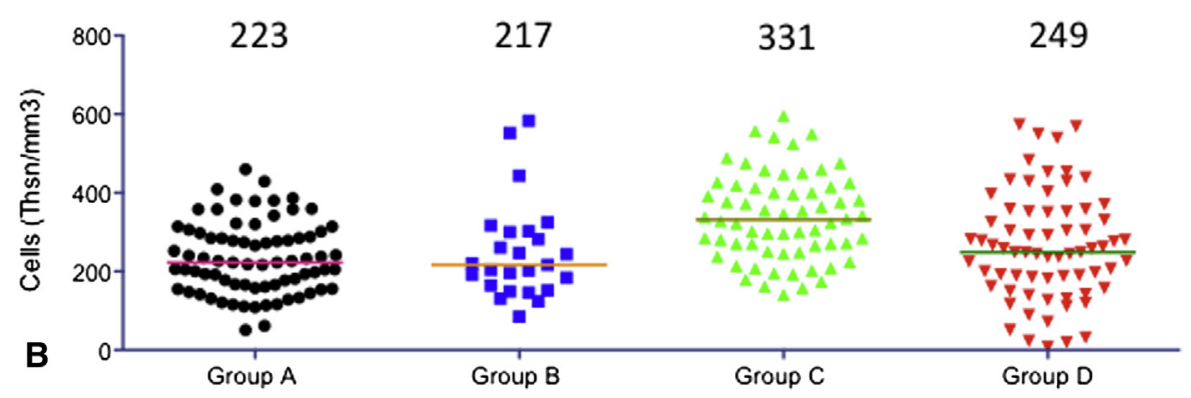

Hematocrit
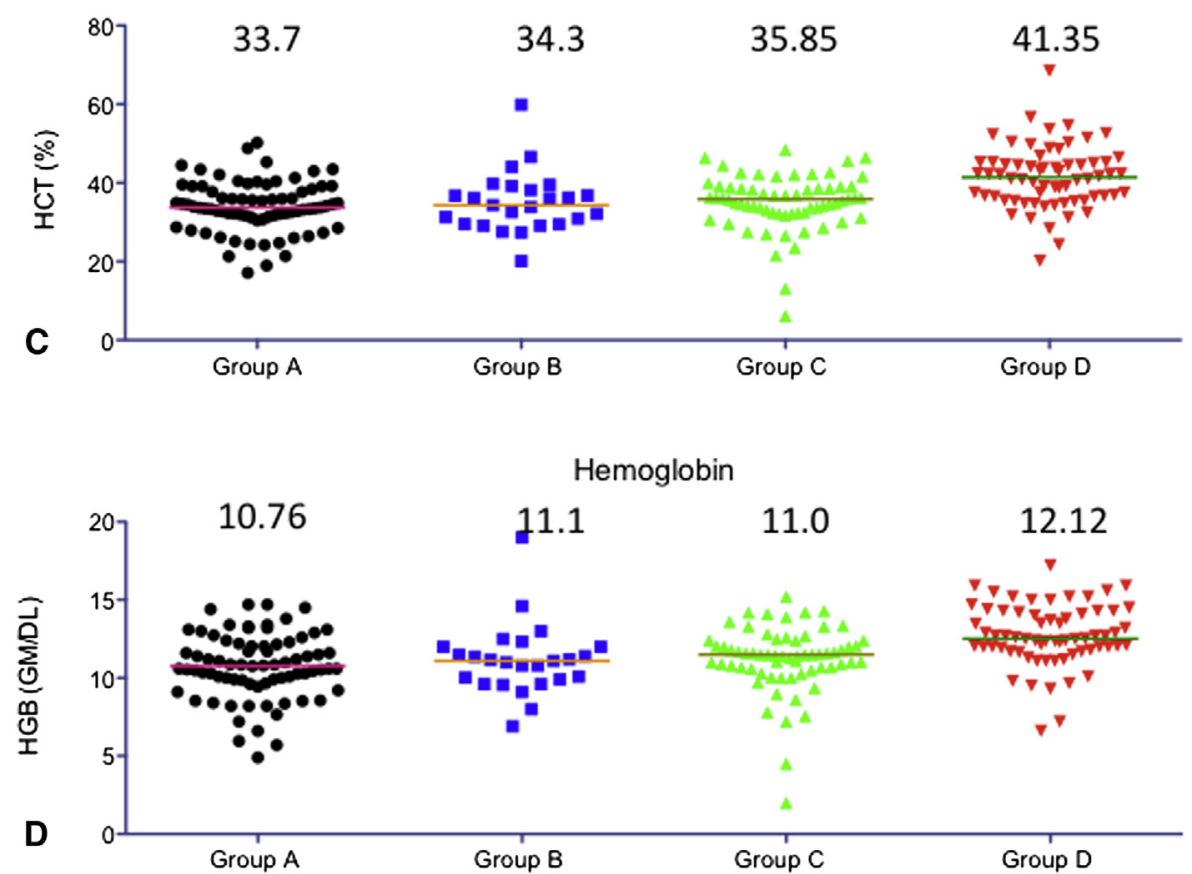

FIGURE 3. Complete blood counts: A, WBC count, (B) platelet counts, (C) hematocrit percentage, and (D) hemoglobin levels were compared among all 4 experimental groups. Horizontal bars indicate the median value that is also shown on the graph. $H C T$, Hematocrit; $H G B$, hemoglobin; $W B C$, white blood cell.

beneficial effect of costimulation blockade in suppressing the xenogeneic immune response and extending xenograft survival. The use of anti-CD40 mAb allowed blockade of the same CD40-CD40L costimulation pathway without encountering the complications of thrombosis. Two available anti-CD40 mAbs were used for this purpose, one generated in mouse (clone $3 \mathrm{~A} 8$ ) and one in recombinant mouse-rhesus chimeric antibody (clone 2C10R4). Neither 


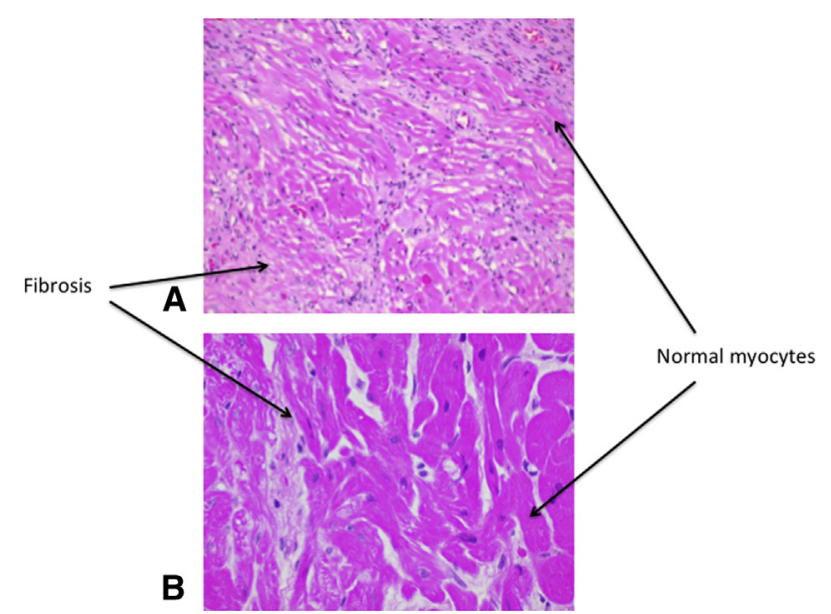

FIGURE 4. Graft histology: Hematoxylin-eosin staining of a biopsy sample from one representative long-term surviving graft each from groups $A$ (A) and D (B) is shown. Most of the group A graft shows fibrosis with some areas of normal myocytes, whereas mostly normal myocytes along with a small area of fibrosis is evident in group D.

clones had the thrombogenic characteristics observed with the anti-CD154 mAb (5C8). The antibody from the $3 \mathrm{~A} 8$ clone was not able to extend graft survival beyond 28 days. ${ }^{9}$ However, the graft survival was significantly prolonged with the $2 \mathrm{C} 10 \mathrm{R} 4$ clone, irrespective of the pig genetics used. A higher dose of this antibody was required in these experiments to produce consistent long-term graft survival, perhaps because of lower affinity of this antibody for baboon cells. We also observed a quicker recovery time from surgery in groups using anti-CD40 mAb. No complications were observed in groups $\mathrm{C}$ or D. A humanized form of anti-CD40 antibody is under production and will be available for clinical use soon (Keith Reimann, personal communication, April 2014).

Additional donor pig genetic modifications used, in addition to alpha Gal knockout, were transgenic expression of human CD46 and TBM. Our results indicate that TBM expression and anti-CD40 treatment were crucial in longterm graft survival. TBM expression successfully avoided $\mathrm{TM}$ and other coagulation issues. It is difficult to dissect the preferential role of either of the 2 modifications used, and further experiments are required for this clarification.

Infections were rarely seen in our animals despite the long-term infusion of maintenance drugs via a jugular catheter. More complications were related to technical problems with the tether system than the recipient baboon themselves. No perioperative graft dysfunction was observed. Some pig viruses, such as cytomegalovirus (CMV), have been shown to affect graft survival in pig allograft models, but we have not seen any active CMV disease in any of our baboons except 1 in which CMV inclusion bodies were found in the testes on necropsy. The source of these inclusion bodies was not determined, and no evidence of active CMV disease was found in this baboon. Other complications experienced over the length of the project included abdominal bleeding, gastrointestinal bleeding, aspiration pneumonia, seizures, thrombocytopenia, and anemia. ${ }^{21}$

Additional technical improvements contributed favorably to aiding graft survival. Video and telemetric monitoring allowed early identification and management of complications expeditiously. ${ }^{22}$ For example, infections were detected early by monitoring recipient temperature via telemetry. Video monitoring allowed continuous surveillance of the baboons and triggered prompt response to emergencies such as infusion pump malfunction, tether/ jacket problems, and seizures. These methods retrospectively enabled us to evaluate the onset of any complication.

\section{CONCLUSIONS}

Significant improvement in graft survival from 179 days $^{23}$ to 8 months, ${ }^{8}$ and to more than 1 year as we reported, by using newly available GE pigs and an immunosuppression regimen based on an nonhuman primate-mouse chimeric anti-CD40 mAb (2C10R4), along with the histology showing preservation of heart architecture in long-term grafts, is encouraging and indicates that these xenograft hearts can be tested in the orthotopic position for their ability to sustain life.

The authors thank the following people and programs for their support: Billeta Lewis, BS, for animal care; Tannia Clak, DVM, for help in performing echocardiography; Michael Eckhaus, DVM, for pathology; Caleb Seavey, for developing analyzing software; Suyapa Ball and Carol Phelps, $\mathrm{PhD}$ (Revivicor, Inc), for the production of GE pigs; Eckhard Wolf and Nikolai Klymiuk (Ludwig-Maximillians University, Munich), for the collaboration on GE pig cells; Keith Reimann, PhD, for providing the anti-CD40 $\mathrm{mAb}$; the Animal Surgery Resource and National Heart, Lung, and Blood Institute, for help with the surgical procedure; the Flow Cytometry Core, National Heart, Lung, and Blood Institute, Division of Veterinary Resource, and National Institutes of Health, for animal care; and Patricia Jackson, for administrative help.

\section{References}

1. Allen SJ, Sidebotham D. Postoperative care and complications after ventricular assist device implantation. Best Pract Res Clin Anaesthesiol. 2012;26:231-46.

2. Phelps CJ, Koike C, Vaught TD, Boone J, Wells KD, Chen SH, et al. Production of alpha 1,3-galactosyltransferase-deficient pigs. Science. 2003;299:411-4.

3. Ekser B, Cooper DK. Overcoming the barriers to xenotransplantation: prospects for the future. Expert Rev Clin Immunol. 2010;6:219-30.

4. Satyananda V, Hara H, Ezzelarab MB, Phelps C, Ayares D, Cooper DK. New concepts of immune modulation in xenotransplantation. Transplantation. 2013;96:937-45.

5. Mohiuddin MM, Singh AK, Corcoran PC, Hoyt RF, Thomas ML 3rd, Lewis BG, et al. One-year heterotopic cardiac xenograft survival in a pig to baboon model. Am J Transplant. 2014;14:488-9.

6. Mohiuddin MM, Corcoran PC, Singh AK, Azimzadeh A, Hoyt RF Jr, Thomas ML, et al. B-cell depletion extends the survival of GTKO.hCD46Tg pig heart xenografts in baboons for up to 8 months. Am J Transplant. 2012;12: 763-71.

7. Zhou H, Iwase H, Wolf RF, Ekser B, Ezzelarab M, Hara H, et al. Are there advantages in the use of specific pathogen-free baboons in pig organ xenotransplantation models? Xenotransplantation. 2014;21:287-90. 
8. Wu G, Pfeiffer S, Schroder C, Zhang T, Nguyen BN, Lea W, et al. Co-stimulation blockade targeting CD154 and CD28/B7 modulates the induced antibody response after a pig-to-baboon cardiac xenograft. Xenotransplantation. 2005; 12:197-208.

9. Mohiuddin MM, Singh AK, Corcoran PC, Hoyt RF, Thomas ML 3rd, Lewis BG, et al. Role of anti-CD40 antibody-mediated costimulation blockade on non-Gal antibody production and heterotopic cardiac xenograft survival in a GTKO.hCD46Tg pig-to-baboon model. Xenotransplantation. 2014;21:35-45

10. Vadori M, Cozzi E. Immunological challenges and therapies in xenotransplantation. Cold Spring Harb Perspect Med. 2014;4:a015578.

11. Griesemer A, Yamada K, Sykes M. Xenotransplantation: immunological hurdles and progress toward tolerance. Immunol Rev. 2014;258:241-58.

12. Tazelaar HD, Byrne GW, McGregor CG. Comparison of Gal and non-Galmediated cardiac xenograft rejection. Transplantation. 2011;91:968-75.

13. Lin CC, Ezzelarab M, Shapiro R, Ekser B, Long C, Hara H, et al. Recipient tissue factor expression is associated with consumptive coagulopathy in pig-to-primate kidney xenotransplantation. Am J Transplant. 2010;10:1556-68.

14. O'Connell PJ. Thrombotic microangiopathy: the next big hurdle for xenotransplantation. J Am Soc Nephrol. 2005;16:2529-30.

15. McGregor CG, Davies WR, Oi K, Teotia SS, Schirmer JM, Risdahl JM, et al. Cardiac xenotransplantation: recent preclinical progress with 3-month median survival. J Thorac Cardiovasc Surg. 2005; 130:844-51.

16. Ekser B, Kumar G, Veroux M, Cooper DK. Therapeutic issues in the treatment of vascularized xenotransplants using gal-knockout donors in nonhuman primates. Curr Opin Organ Transplant. 2011;16:222-30.

17. Bluml S, McKeever K, Ettinger R, Smolen J, Herbst R. B-cell targeted therapeutics in clinical development. Arthritis Res Ther. 2013;15(Suppl 1):S4.

18. Larsen CP, Elwood ET, Alexander DZ, Ritchie SC, Hendrix R, Tucker-Burden C, et al. Pillars article: long-term acceptance of skin and cardiac allografts after blocking CD40 and CD28 pathways. Nature. 1996;381:434-8. 1996. J Immunol. 2011;186:2693-7.

19. Buhler L, Alwayn IP, Appel JZ III, Robson SC, Cooper DK. Anti-CD154 monoclonal antibody and thromboembolism. Transplantation. 2001;71:491.

20. Koyama I, Kawai T, Andrews D, Boskovic S, Nadazdin O, Wee SL, et al. Thrombophilia associated with anti-CD154 monoclonal antibody treatment and its prophylaxis in nonhuman primates. Transplantation. 2004;77:460-2.

21. Corcoran PC, Horvath KA, Singh AK, Hoyt RF Jr, Thomas ML III, Eckhaus MA, et al. Surgical and nonsurgical complications of a pig to baboon heterotopic heart transplantation model. Transplant Proc. 2010;42:2149-51.

22. Horvath KA, Corcoran PC, Singh AK, Hoyt RF, Carrier C, Thomas ML III, et al. Left ventricular pressure measurement by telemetry is an effective means to evaluate transplanted heart function in experimental heterotopic cardiac xenotransplantation. Transplant Proc. 2010;42:2152-5.

23. Kuwaki K, Tseng YL, Dor FJ, Shimizu A, Houser SL, Sanderson TM, et al. Heart transplantation in baboons using alpha1,3-galactosyltransferase gene-knockout pigs as donors: initial experience. Nat Med. 2005;11:29-31.

\section{Discussion}

Dr Joren Madsen (Boston, Mass). I congratulate the speaker and the Society for recognizing the importance of this work. Enthusiasm in xenotransplantation has waxed and waned over the last 20 years. Dr Shumway used to say, half jokingly but half seriously, that xenotransplantation was the future of heart transplantation and always would be. However, these compelling new findings suggest that the future of xenotransplantation may be closer than we all thought. Indeed, achieving a greater than 500-day survival of a pig heart in a discordant baboon recipient sets a new standard for the field and allows us to begin thinking about human application again.

My major concern in reading your article was your use of the heterotopic heart transplant model in which the heart graft is not life sustaining and graft survival times can be easily overestimated. However, your use of the innovative telemetry techniques to continuously monitor intracardiac pressures has tempered those concerns. I have 3 questions that relate to your recipients in group D.

What was the specific immune or nonimmune mechanism that led to the loss of 2 of the 5 recipients in group D? Will additional immunotherapeutics or genetic modifications be required to achieve $100 \%$ survival?

Dr Mohiuddin. The 2 animals that rejected in group D were explanted. One of them had long-term fever with no cause to be found, and because of strict animal care rules, we had to euthanize this animal. This animal showed no significant necropsy finding but had some inclusion CMV bodies in its testes. There was no evidence of any active CMV disease in this animal. The other animal that we explanted had repeated episodes of ventricular fibrillation, and we took the heart out to satisfy our Animal Care and Use Committee concerns.

In both these hearts, we did see a lot of fibrosis and myocyte damage on histology, but there were areas preserved that had normal myocardium. It is hard to pinpoint the exact cause of rejection, and all these animals had high levels of antibodies against non-GAL antigens. It is possible that both the antibody and the TM played significant roles in the delayed rejection of these hearts. Additional expression of human genes to avert TM and careful adjustment of anti-CD40 dose may yield an even better survival.

Dr Madsen. Many investigators believe that successful xenotransplantation will require the induction of immune tolerance. Do you believe or have any evidence that your protocol resulted in immune tolerance, and if so, would you consider weaning all drugs at a certain time point to limit the morbidity and mortality related to chronic immunosuppression?

Dr Mohiuddin. In one of the animals, which has survived for approximately 600 days now, we have done some preliminary studies. We have done mixed lymphocyte reaction assays from the lymphocytes and saved cells from the donor pig, and we have seen that this animal was hyporesponsive to the donor-specific antigen. But when we tested responses against cells from a third-party pig, these cells were responsive. So there is an element of "tolerance" in there, but we need to do a lot more studies to evaluate that. We have already started to taper the immunosuppressive drugs in 2 of 3 surviving animals. In explanted grafts, we have found no evidence of chronic vasculopathy.

Dr Madsen. The last question concerns infections. Other have found that reactivation of pig and even baboon CMV seems to have serious adverse effects in pig-to-baboon xenotransplantation. Given your exclusive use of SPF animals, are you concerned that the same excellent results may not be achieved in non-SPF animals or, for that matter, in humans?

Dr Mohiuddin. We tested the levels of the non-Gal antibodies in SPF baboons, and they were found to be comparable to levels found in humans. As far as the antibody levels, we are satisfied with what we have, but I fully acknowledge your concern for CMV. Although we have not seen active CMV disease in any of our animals, the literature shows that this is a big concern, and we will have to keep a close eye on that.

Dr Madsen. Thank you and congratulations.

Dr R. Duane Davis (Durham, NC). This is an interesting series of experiments. Let me follow up a little bit on what Joren was asking in terms of the antibody-mediated rejection assessment on the organs that are still working. Have you been following 
the anti-swine antibody titers? You mentioned you started with low-titer baboons as recipients. How low were they? What has happened over the period of time in terms of the development of anti-pig, non-GAL antibodies?

Dr Mohiuddin. As I mentioned earlier, the non-Gal antibody levels in SPF baboons are lower than in the conventional baboons and comparable to the levels in humans. The levels vary from baboon to baboon. We give 4 doses of rituximab that completely takes care of B cells, and these B cells do not return until day 60. After that period, we do see somewhat higher titers of antibodies than their baseline levels. In the earlier groups, we did find antibody deposition in the heart, but what role they are playing is not evident.

Dr Davis. When you say by using that dose you are clearing all of the B cells, are you looking at the B1 cells in the peritoneal cavity, and along those lines are you looking at the central compartment? Obviously, you have plasma cells and some of the other long lines that antiCD20 does not actually address.

Dr Mohiuddin. Exactly, that is our concern also, because CD20 does not take care of plasma cells, people have shown the role of bortezomib in eliminating plasma cells, which we have not tried. A single dose of rituximab can eliminate the peripheral circulating $\mathrm{B}$ cells. But what we have shown earlier, and Chris McGregor's group, is that you need at least 4 doses to completely wipe out B cells in all compartments.

Dr Y. Joseph Woo (Philadelphia, Pa). Do the standard xenotransplantation models entail continuous heparin anticoagulation?
Dr Mohiuddin. Yes, and we have seen a beneficial effect of it. We keep these animals on tether and continuous heparin infusion.

Dr Woo. Among the prior models that yielded survival only up to 500 days, did these involve anticoagulation? How much is the anticoagulation benefiting your model?

Dr Mohiuddin. We monitor their ACT and try to keep the level twice the level of the baseline number, and we maintain it throughout. Others have tried various forms of anticoagulation for variable periods of time; some of them have tried for a few months and others for only a few weeks. We are the only ones, I think, who have used it on a continuous basis.

Dr Woo. So it may be contributing significantly?

Dr Mohiuddin. Definitely.

Dr Woo. In this heterotopic model, can the grafts undergo an endovascular endomyocardial biopsy?

Dr Mohuddin. Yes, the histology results I showed in my presentation are the 1-year biopsy results from our long-term graft.

Dr Woo. They weren't the final pathology?

Dr Mohiuddin. The long-term graft results were biopsy results, but for the other groups, we have explanted the heart, and the results shown are from the final pathology.

Dr Woo. Did you ever modify the anti-rejection regimen on the basis of biopsy findings?

Dr Mohiuddin. Not really, because the major problem is the antibodies in xenotransplantation. Our main goal is to first tackle the antibody and the molecules that are incompatible with this model. We do initiate rescue therapy with steroids when we see onset of rejection, but this therapy has not helped us so far. 